\title{
The Canadian Partnership for Tomorrow Project: building a pan-Canadian research platform for disease prevention
}

\author{
Marilyn J. Borugian PhD, Paula Robson PhD, Isabel Fortier PhD, Louise Parker PhD, \\ John McLaughlin PhD, Bartha Maria Knoppers PhD, Karine Bédard MA, Richard P. Gallagher MA, \\ Sandra Sinclair MSc, Vincent Ferretti PhD, Heather Whelan MSc, David Hoskin PhD, \\ John D. Potter MD PhD
}

Previously published at www.cmaj.ca

$\mathrm{A}$ $\mathrm{s}$ the proportion of the population over age 65 increases in Western countries, the burden of cancer ${ }^{1}$ and other chronic diseases is also increasing. If advances in preventing these diseases are to be realized, better information is needed about their causes and the antecedents of the causes. For example, although it is known that many sporadic cancers are caused by a combination of lifestyle factors, exposure to environmental carcinogens and individual genetic makeup, ${ }^{2,3}$ detailed knowledge about the interplay among these factors is lacking.

Much of our current knowledge about the causes of cancer and most relatively rare chronic diseases has come from retrospective case-control studies, in which the characteristics of patients (cases) are compared with those of age- and sexmatched people who do not have the disease (controls). This design has strengths but also a number of weakneses, including potential recall bias and selection bias $^{4}$ (Table 1). To address some of these weaknesses, in particular recall bias and the temporal relation between risk factors and outcomes, prospective cohorts are helpful because participants are enrolled before the onset of disease. In studies with a prospective cohort design, large numbers of participants, who generally have not had cancer or any other significant diagnosis, are recruited and followed over a long time, periodically providing updated health and lifestyle information and biologic samples. Layers of data and samples accumulate over time, allowing an exploration of why cancer develops in some people within the cohort but not others. ${ }^{6}$ The disadvantages of such a design (Table 1) are cost and time, as it may be a decade or more before major results are obtained. Fortunately, many shorterterm results are also available, such as information on screening attendance and information on the frequency of major risk factors and health states, as well as environmental and individual determinants of these risk factors, all of which are useful for planning various health services. Furthermore, because many diseases can be studied simultaneously, the cost over time per health outcome studied is substantially lower than the cost of case-control studies for a comparable number of participants.

In this paper, we describe the rationale for, challenges associated with and methods being used in a new panCanadian cohort for the study of cancer and chronic disease.

\section{Key points}

- The Canadian Partnership for Tomorrow Project is a pan-Canadian initiative to learn more about the causes of cancer and other chronic diseases.

- This project will follow 300000 Canadians on a long-term basis.

- Data collection methods include questionnaires, blood and urine samples, and physical measurements to provide the foundation for hundreds of studies.

- The aim is to understand how environment, lifestyle and genetics contribute to chronic diseases and to use this understanding to inform prevention strategies.

This cohort will, in time, form the foundation for a major research platform for the study of disease causation, both nationally and internationally.

\section{Design}

A strategic partnership has been formed to establish a large prospective cohort for the study of the causes of cancer and other chronic diseases in Canada. This partnership, the Canadian Partnership for Tomorrow Project, aims to develop a comprehensive, long-term, pan-Canadian health research platform with sufficient statistical power to examine the complex interplay of genetic and environmental factors that leads to the development of important chronic diseases in the Canadian population. ${ }^{7}$ The Canadian Partnership for Tomorrow Project

From the Cancer Control Research Program (Borugian, Gallagher), British Columbia Cancer Agency and School of Population and Public Health, University of British Columbia, Vancouver, BC; Alberta Health Services - Cancer Care (Robson, Whelan), Edmonton, Alta.; School of Public Health (Robson), University of Alberta, Edmonton, Alta.; Public Population Project in Genomics (Fortier), Université de Montréal, Montréal, Que.; Cancer Care Nova Scotia (Parker), Dalhousie University, Halifax, NS; Population Studies and Surveillance (McLaughlin, Sinclair), Cancer Care Ontario, Toronto, Ont. Dalla Lana School of Public Health (McLaughlin), University of Toronto, Toronto, Ont.; Centre of Genomics and Policy (Knoppers), McGill University, Montréal, Que.; CARTaGENE (Bédard), Université de Montréal, Montréal, Que.; Ontario Institute for Cancer Research (Ferretti), Toronto, Ont.; Capita District Health Authority and Dalhousie University (Hoskin), Halifax, NS; and Fred Hutchinson Cancer Research Center (Potter), Seattle, USA

CMAJ 2010. DOI:10.1503/cmaj.091540 
comprises a confederation of provincial and regional cohorts (Table 2) in British Columbia, Alberta, Ontario, Quebec and Atlantic Canada (Nova Scotia, New Brunswick, Prince Edward Island, and Newfoundland and Labrador). The operational objective is to enrol 250000 to 300000 Canadians aged 35-69 years by 2012, and enrolment is already under way. A number of task forces and working groups have been established to address issues related to ethics, privacy, harmonization, information technology, sample processing and definition of environmental exposures of interest (Figure 1).

\section{Participants}

Canadian residents are eligible for a provincial or regional component of the project if they reside in the province or region and meet the cohort's age criteria (Table 1). The mechanisms for identifying potential participants vary among jurisdictions and include random selection from population-based data, purchase of mailing lists for specific geographic areas, random-digit dialing and word of mouth.

Project staff contact potential participants by letter with an invitation to join, although volunteers will be accepted in some cases. The sources of contact information vary by region, and the impact of this variation will be monitored regularly to help ensure that the resulting cohort is relatively representative of the Canadian population. All five regional cohort teams have agreed to the core measures, and individual provinces or regions will schedule the acquisition of data, biologic specimens and physical measurements according to the most efficient methods of local practice.

Initially, those who express an interest in participating make an appointment to come to an assessment centre for 90-120 minutes. During this visit, a project staff member explains the study to the participant, who provides written informed consent and completes an epidemiologic questionnaire on lifestyle, health

Table 1: Strengths and limitations of case-control and prospective cohort study designs ${ }^{5}$

\begin{tabular}{ll}
\hline Strengths & \multicolumn{1}{c}{ Limitations } \\
\hline Case-control studies & $\begin{array}{l}\text { Difficult to examine } \\
\text { temporality }\end{array}$ \\
\hline Relatively quick & $\begin{array}{l}\text { Potentially prone to bias } \\
\text { (selection and recall) }\end{array}$ \\
\hline Relatively inexpensive & \\
\hline $\begin{array}{l}\text { Can be used to examine } \\
\text { multiple factors }\end{array}$ & $\begin{array}{l}\text { Expensive and time- } \\
\text { consuming }\end{array}$ \\
\hline $\begin{array}{l}\text { Prospective cohort studies } \\
\text { multiple outcomes }\end{array}$ & $\begin{array}{l}\text { Losses to follow-up over } \\
\text { time }\end{array}$ \\
\hline $\begin{array}{l}\text { Allow for prediagnostic } \\
\text { specimens }\end{array}$ & \\
\hline $\begin{array}{l}\text { Minimal bias in selection, recall } \\
\text { and ascertainment of exposure } \\
\text { Can be used to examine } \\
\text { temporal relations between } \\
\text { exposure and disease }\end{array}$ & \\
\hline
\end{tabular}

events and other factors. Physical variables are measured, including sitting height, standing height, weight, percentage body fat (by bioelectrical impedance), waist circumference, hip circumference, grip strength, blood pressure and resting heart rate. Bone density by ultrasonography and lung function by spirometry are in the extended variable set, which consists of variables that are collected, in a consistent manner, by two or more regions but are not a required part of the protocol for all regions. Data that may be important for later interpretation of these physical measures are also collected. Eligible participants also provide biologic specimens (primarily blood). As recruitment proceeds, it may prove more cost-effective for the component cohort teams to collect data in a different sequence from that noted above. For example, there might be initial concentration on completion of enrolment questionnaires and collection of biologic specimens, with physical measurements being obtained later.

\section{Biologic specimens}

Specimens of urine and of venous blood (nonfasting; 36-50 $\mathrm{mL}$, depending on the province or region), the latter fractionated into multiple aliquots of plasma, serum, buffy coat and red blood cells, are stored at $-80^{\circ} \mathrm{C}$ in mechanical freezers or in liquid nitrogen in local repositories. Some provinces or regions are collecting spots of whole blood for storage on Whatman FTA cards (Whatman International Limited, Kent, United Kingdom) at room temperature, whereas others are storing whole blood for future extraction of lymphocytes. In addition, spot urine samples and toenail clippings may be collected. Ultimately, we anticipate that specimens stored in local provincial biorepositories will be mirrored within a national biorepository.

\section{Follow-up and outcomes}

After enrolment, cohort members will be followed with both active and passive methods for at least 25 years. Active follow-up may include requests for additional questionnaire data, biologic samples or physical measurements. Passive follow-up will involve linking to provincial health care data systems (for example, registries or provincial health services databases) to determine health outcomes and to take full advantage of Canada's integrated health information systems. Because outcomes linkages will be performed at the provincial level, there could be some variation in methods, but as much as possible, the linkages will be conducted in a consistent manner. Such linkages will be subject to the usual quality control processes in place in each provincial cancer registry.

\section{Making Canada's cohort unique}

Cohort studies of cancer and other chronic diseases are under way in many countries..$^{8-10}$ Cohorts of 200000 or more participants that are established or being planned are shown in Table 2. The question therefore arises of why Canada should invest in such a cohort. This initiative has three unique aspects.

First, the Canadian Partnership for Tomorrow Project will include a major emphasis on the effects of exogenous or environmental factors on the risk of cancer and chronic disease. 
The Partnership is building a prospective platform that will integrate environmental measures and lifestyle risk factors to study their interaction with genetic and epigenetic risk factors. To this end, the Occupation and Environment Expert Advisory Group is providing expertise on the collection of environmental data and samples and is planning to use existing Canadian data resources related to environmental exposures of interest. For example, the collection of a detailed residence history for each participant offers the potential to map possible exposures using postal codes and long-established geographic information systems databases for the locations of fixed sources of carcinogens and mobile sources of potential morbidity, such as air and water pollution.
Second, through linkages to provincial health utilization data, this Canadian cohort study will allow researchers to study chronic diseases other than cancer in relation to health services usage and outcomes data generated by provincial health services programs. This process will be crucial for chronic diseases that are not recorded on disease registries and that may not be noted on death certificates. Linkage with the emerging national tumour-tissue collection program, the Canadian Tumour Repository Network, will result in further valuable data.

Finally, the Canadian Partnership for Tomorrow Project is structured such that each province or region (Table 2), in addition to collecting core information measurements and specimens, will be encouraged to make use of data sources

Table 2: Cohort studies of cancer and chronic disease, including component studies of Canadian Partnership for Tomorrow Project

\begin{tabular}{|c|c|c|c|c|c|c|}
\hline Study name & $\begin{array}{c}\text { Type of } \\
\text { participants }\end{array}$ & $\begin{array}{l}\text { Target or final } \\
\text { (current) no. of } \\
\text { participants* }\end{array}$ & $\begin{array}{l}\text { Age, yr, } \\
\text { min-max }\end{array}$ & $\begin{array}{l}\text { Country or } \\
\text { Canadian region of } \\
\text { residence }\end{array}$ & Current status & $\begin{array}{l}\text { Year } \\
\text { recruitment } \\
\text { started }\end{array}$ \\
\hline $\begin{array}{l}\text { European Prospective } \\
\text { Investigation into Cancer and } \\
\text { Nutrition }\end{array}$ & Individuals & 520000 & $30-70$ & $\begin{array}{c}\text { Sweden, Italy, } \\
\text { Netherlands, United } \\
\text { Kingdom, Germany, } \\
\text { Norway, France, } \\
\text { Greece, Spain, } \\
\text { Denmark }\end{array}$ & Follow-up & 1993 \\
\hline Multiethnic Cohort Study & Individuals & 215251 & $45-75$ & United States & Follow-up & 1993 \\
\hline NIH-AARP Diet and Health Study & Individuals & 567169 & $50-69$ & United States & Follow-up & 1995 \\
\hline Million Women Study & Individuals & 1300000 & $50-64$ & United Kingdom & Follow-up & 1997 \\
\hline 45 and Up Study & Individuals & 250000 & $\geq 45$ & Australia & Follow-up & 2006 \\
\hline Cancer Prevention Study, cycle 3 & Individuals & 500000 & $30-65$ & United States & Recruitment & 2007 \\
\hline UK Biobank & Individuals & 500000 & $40-69$ & United Kingdom & Recruitment & 2007 \\
\hline LifeGene & Families & 500000 & $\leq 55$ & Sweden & Development & 2010 \\
\hline $\begin{array}{l}\text { National Guard Health Affairs } \\
\text { Bio-bank }\end{array}$ & & 200000 & NA & Saudi Arabia & Development & $\begin{array}{c}\text { No } \\
\text { information }\end{array}$ \\
\hline \multicolumn{7}{|l|}{$\begin{array}{l}\text { Canadian Partnership for } \\
\text { Tomorrow Project }\end{array}$} \\
\hline $\begin{array}{l}\text { BC Generations Project } \\
\text { www.bcgenerationsproject.ca }\end{array}$ & Individuals & $40000(4722)$ & $40-69$ & British Columbia & Recruitment & 2009 \\
\hline $\begin{array}{l}\text { Atlantic Partnership for } \\
\text { Tomorrow's Health } \\
\text { www.atlanticpath.ca }\end{array}$ & Individuals & $30000(6005)$ & $40-69$ & Atlantic $¥$ & Recruitment & 2009 \\
\hline
\end{tabular}

Note: NA = not applicable, NIH-AARP = National Institutes of Health - American Association of Retired Persons.

*Data on current enrolment (as of Mar. 20, 2010) are provided for Canadian Partnership for Tomorrow Project.

tAt least 200000 participants.

¥Nova Scotia, New Brunswick, Prince Edward Island, Newfoundland and Labrador. 
unique to its catchment area and thus to extend and augment the national effort.

\section{Key deliverables}

The Canadian Partnership for Tomorrow Project is establishing a platform to help support research in cancer, as well as other chronic diseases, in Canada and internationally over the coming decades. This effort is guided by the prevention-related objectives of the Canadian Strategy to Control Cancer, ${ }^{11}$ particularly "to reduce the expected number of new cases of cancer among Canadians" and "to lessen the likelihood of Canadians dying from cancer." The Partnership is also motivated by the fact that a common constellation of risk factors leads to the development of cardiovascular disease, diabetes mellitus and other important chronic diseases. The work described in this paper will meet the key research goals presented in Box 1 .

\section{Key challenges}

To date, needs for funding have been met in three ways: by obtaining major support from the Canadian Partnership
Against Cancer, an independent organization funded by the federal government to accelerate action on cancer control in Canada; by reducing costs, which has been achieved by leveraging and harmonizing existing regional cohort initiatives; and by forming strategic partnerships within some provinces to help with data collection and to obtain significant additional funding. Nonetheless, ensuring sustainable long-term funding continues to be a challenge that must be addressed at the national level. Funding for individual research projects that wish to use the data gathered will be the responsibility of the requesting research group.

When the Partnership was formed, harmonization was an important challenge because researchers using the data and biospecimens must be confident that materials collected across Canada are directly comparable. To ensure adequate harmonization, a task force was struck to define the "core" questionnaire items, physical measurements and biospecimens to be collected. The provinces and regions have now agreed upon these core items, along with standard operating procedures for acquiring data and for obtaining, processing and storing specimens.

Regulations and codes concerning confidentiality, privacy, research ethics, and legal and social issues differ across the

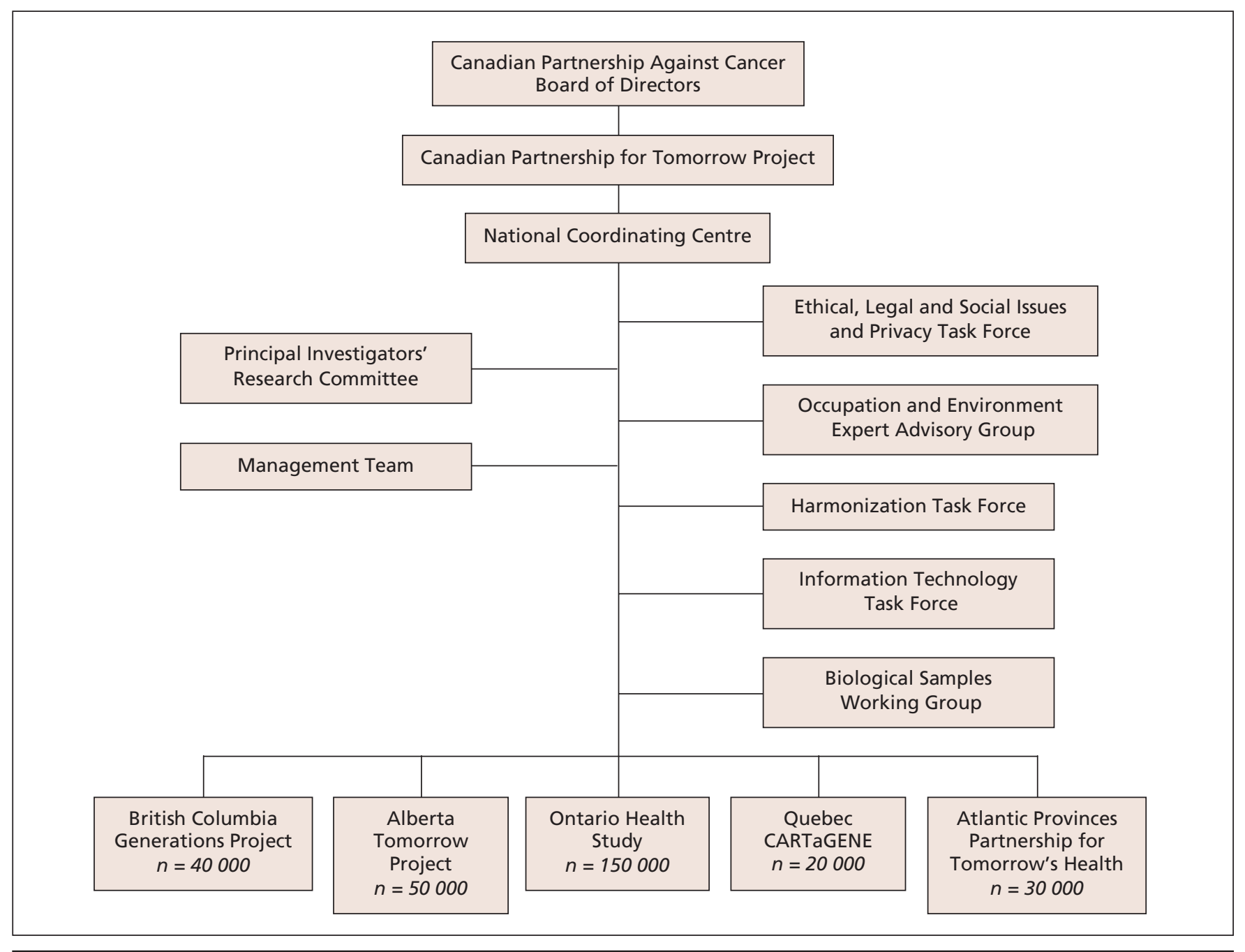

Figure 1: Overview of the Canadian Partnership for Tomorrow Project. 


\section{Box 1: Key deliverables of the Canadian Partnership} for Tomorrow Project

For research:

- A "population laboratory" for leading-edge, population-based basic and translational research related to cancer and chronic diseases within Canada.

- A bank of biologic specimens and related personal exposure data that can be linked with provincial data on health care utilization.

- A resource and legacy for future generations of Canadians that will continue to yield valuable information about health and risks of disease.

For policy, prevention and care:

- A platform that enables improvement in the control of cancer and the incidence of chronic disease through identification of new risk factors that may be modified through preventive interventions.

- A platform that enables reduction in disease-related mortality through detection of new prognostic factors and markers of early disease.

- An observatory for tracking the results of "natural experiments" occurring over time related to interprovincial variations in the introduction of new technologies, new programs for preventing disease or methods of health care delivery.

- A mechanism for predicting future needs for care, through the tracking of factors that are likely to predict future incidence of disease and related mortality, and the associated costs.

- A platform for investigating the policy issues associated with population studies.

- A mechanism for monitoring uptake of screening and prevention initiatives by the Canadian population and the impact of these initiatives.

country and are for the most part in the domain of provincial governments. To ensure that legislation, regulations and practices are observed and respected, while optimizing scientific benefit from the cohorts, an Ethical, Legal and Social Issues and Privacy Task Force was struck. This task force has ensured that patient information and consent forms are uniform across the country and that procedures for collecting, storing and accessing data and specimens meet the highest standards of privacy and confidentiality. This task force is now developing policies for data access and prioritization.

Epidemiologic information and specimen annotation must be compatible across Canada if the research platform is to function efficiently. The Information Technology Task Force has designed software for the acquisition of data, physical measurements and specimens, and this software has been harmonized across provinces to ensure uniform quality of recorded data while protecting the confidentiality of participants. All "content-related" information (questionnaire responses, measurements and specimens) is deidentified at the time of acquisition, and the "administrative" information is securely maintained so that re-contact with participants and data linkage to provincial health databases are possible.
In conclusion, harmonization of data and practices forms the keystone of this unique Canadian cohort. Cooperation among regions has allowed consistency across core variables, as well as variation across scientific interests. Data from the cohort will enable a wide range of research and will be accessible to and used by investigators from diverse disciplines.

\section{This article has been peer reviewed.}

Competing interests: Marilyn Borugian's salary as the director of the British Columbia Generations Project (the BC component of the Canadian Partnership for Tomorrow Project) is supported by a grant from the Canadian Partnership Against Cancer. None declared for other authors.

Contributors: All authors contributed to manuscript conception and design. Marilyn Borugian, John McLaughlin and Richard Gallagher contributed to writing the initial drafts of the article, revising the manuscript and responding to editors and reviewers. Paula Robson, Isabel Fortier, Louise Parker, Bartha Maria Knoppers, Karine Bédard, Sandra Sinclair, Vincent Ferretti, Heather Whelan, David Hoskin and John Potter were involved in reviewing drafts and suggesting revisions. Isabel Fortier provided information about cohorts in other countries. Louise Parker provided input to responses to editors and reviewers. Bartha Maria Knoppers provided expert advice on ethical and governance issues. Vincent Ferretti provided information about information technology challenges. John D. Potter made suggestions about responses to editors and reviewers and provided information about other cohorts around the world. All authors approved the final version of the manuscript submitted for publication.

Acknowledgements: The authors are representative of and acknowledge the contributions of the many individuals in each province who have contributed to the scientific and operational features of this program.

The authors gratefully acknowledge funding from the Canadian Partnership Against Cancer, Canary Foundation, Alberta Cancer Foundation/Alberta Health Services, Ontario Institute for Cancer Research, Ontario Agency for Health Protection and Promotion, Cancer Care Ontario, Genome Canada and Genome Quebec.

\section{REFERENCES}

1. Canadian cancer statistics. Toronto (ON): Canadian Cancer Society and National Cancer Institute of Canada; 2009.

2. Food, nutrition, physical activity and the prevention of cancer: a global perspective. Washington (DC): World Cancer Research Fund Panel and American Institute for Cancer Research; 2007.

3. Schottenfeld D, Fraumeni JF, eds. Cancer epidemiology and prevention. 3rd ed New York (NY): Oxford University Press; 2006.

4. Parr CL, Hjartaker A, Laake P, et al. Recall bias in melanoma risk factors and measurement error effects: a nested case-control study within the Norwegian Women and Cancer Study. Am J Epidemiol 2009;169:257-66.

5. Hennekens CH, Buring JE. Epidemiology in medicine. Boston (MA): Little, Brown and Company; 1987.

6. Potter JD. Toward the last cohort. Cancer Epidemiol Biomarkers Prev 2004;13: 895-7.

7. Partnership + momentum $=$ progress. Progress report winter 2009 . Toronto $(\mathrm{ON})$ Canadian Partnership Against Cancer; 2009. Available: www.partnershipagainst cancer.ca/sites/default/files/documents/CPAC_ProgressRep08Eng_W.pdf (accessed 2009 Aug. 17)

8. Riboli E, Kaaks R. The EPIC Project: rationale and study design. European Prospective Investigation into Cancer and Nutrition. Int J Epidemiol 1997; 26(Suppl 1):S6-14.

9. The Million Women Study. Design and characteristics of the study population. The Million Women Study Collaborative Group. Breast Cancer Res 1999;1:73-80.

10. Peakman TC, Elliott P. The UK Biobank sample handling and storage validation studies. Int J Epidemiol 2008;37(Suppl 1):i2-6.

11. Canadian Strategy for Cancer Control. The Canadian strategy for cancer control: a cancer plan for Canada [discussion paper]. Toronto $(\mathrm{ON})$ : The Canadian Cancer Society; 2006. Available: www.cancer.ca. (accessed 2009 Aug. 17).

Correspondence to: Dr. Marilyn J. Borugian, Cancer Control Research Program, BC Cancer Agency, 675 West 10th Ave., Vancouver BCV5Z 1L3; mborugian@bccrc.ca 